\title{
Factors affecting the use of computers in the classroom: four case studies
}

\author{
Wim Veen
}

Institute of Education

Utrecht University, The Netherlands

\begin{abstract}
The decision of teachers whether or not to use computers depends on two basic categories of factors: factors at school level and factors at teacher level. However, teacher factors appear to be more significant than the factors at school level. Teachers have strong beliefs in respect to the content of their subject matter as well as to the pedagogy. The case-studies in one school (1989-1993) described here show that those beliefs appear to change only very slowly. Teachers adopt new media if they can use them in accordance with their existing beliefs and practice. The findings of this study coincide to a large extent with the results of many other studies of classroom practice.
\end{abstract}

Keywords: attitudes, case studies, classroom practice, innovation, pedagogy

\section{INTRODUCTION}

Between 1989 and 1991 four case-studies were undertaken to explore the day-to-day practice of teachers in one school who were introducing the use of computers in their classrooms. The teachers involved were provided with a computer at home, one computer and a transviewer in their classroom, and a fully fledged computer laboratory. The selected 


\section{Integrating information technology into education}

teachers included both average and experienced teachers who were novices in the field of information technology in education. The four teachers were given a standard in-service training course on computer-assisted teaching to bring them as a group to a same level of computer competence. After the course all further support by the researchers was withdrawn. The teachers were free to use or not to use the computers in their classrooms and at home. The main research question was

"If they have adequate resources, what are these teachers going to do with computers at school and at home and can their activities be explained?"

\section{THE RESEARCH METHOD}

To implement the case-study approach [1] different sources of data were used: questionnaires, teachers' diaries, different types of interviews, classroom observations and research group deliberations. (See Table 1.) The teachers kept semi-structured diaries; teachers were interviewed every two or three weeks about the entries in their diaries. Empirical data of classroom activities were collected by observations of computer assisted lessons. Finally, in-depth interviews were conducted every six months during which the teachers reflected on their latest activities.

\begin{tabular}{|c|c|c|c|c|c|c|}
\hline & French & English & History & Geography & Informants & Total \\
\hline $\begin{array}{c}\text { Classroom } \\
\text { observations }\end{array}$ & 16 & 8 & 19 & 13 & - & 56 \\
\hline Diaries & 182 & 62 & 167 & 118 & - & 529 \\
\hline Initial interviews & 1 & 1 & 2 & 2 & 3 & 9 \\
\hline $\begin{array}{c}\text { Interviews every } \\
\text { fortnight }\end{array}$ & 26 & 16 & 26 & 22 & - & 90 \\
\hline $\begin{array}{c}\text { Interviews every six } \\
\text { months }\end{array}$ & 3 & 3 & 3 & 3 & 9 & 21 \\
\hline $\begin{array}{c}\text { Follow-up } \\
\text { interviews }\end{array}$ & 2 & 2 & 2 & 2 & 6 & 14 \\
\hline Questionnaires & 2 & 2 & 2 & 2 & - & 8 \\
\hline $\begin{array}{c}\text { Plenary meetings in } \\
\text { school }\end{array}$ & - & - & - & - & - & 3 \\
\hline
\end{tabular}

Table 1: Sources of data used in the research 
For a better understanding of the context in which the teachers worked, the principal, the technical assistant and the IT co-ordinator were interviewed every six months. All interviews and classroom observations were audio-taped and transcribed. In order to eliminate bias in the collected data, all interview transcripts have been analysed by a different member of the research group. Researchers rotated classroom observations as well as interviews. In weekly meetings the research group discussed the collected data to reach a high degree of inter-subjectivity. In this way, from the fall of 1989 until January 1991 all the computer-related activities of the teachers were comprehensively described and analysed.

After this intensive period of data collection and analysis, there was a follow-up period of limited data collection from 1991 until June 1993; the teachers and the three informants were interviewed once a year.

\section{The school at the start of the research}

The four teachers (of French, English, Geography and History) all worked at a medium-sized secondary school (800 students) in an urbanized region in the centre of the Netherlands. The school enrols students of a variety of levels and was not seen as being unusual relative to other such general secondary schools. Certainly the school had no particular history of innovative practice. The school is known for its relatively traditional whole-group classroom teaching methods. Lessons are generally 45 minutes in length and students have three hours per week available for study help, homework supervision, and some free choice activities. The teaching staff is predominantly composed of teachers with a considerable amount of experience and mobility among the staff members is not usual.

The school had two computer rooms before the start of the research period. One was the standard configuration available in all secondary schools in The Netherlands, the other a small room with eight old microcomputers. Typically the computers were only used for the teaching of the required information technology course, consisting of general lessons in programming. The area of the school where the French teachers worked had an additional set of three computers, used for drill and practice exercises in French.

At the start of the research, the school had no definite policy about computer assisted learning. There was a teacher serving as a technical assistant for the use of the computers, but he had no formal task definition. However, by 1989 the new school principal held a positive view on computer-assisted learning. She believed that computers offered the possibility for more individualized learning and for more of an orientation toward inquiry learning within the school. Thus she supported the 
involvement of the school in the research, partly because she believed that the study could have a positive influence on the 'face of the school'. The teachers who participated in the study, however, had no release time available for the research.

\section{The teachers at the start of the research}

The four teachers all had good reputations. Three had about 20 years' teaching experience, while one, the history teacher, had 5 years' teaching experience. According to their own self-appraisals, roughly $80 \%$ of their lessons were "teacher-centred." Using a standard questionnaire consisting of 90 statements, the teachers could be compared to 95 Dutch teachers who had previously responded to the questionnaire on 11 issues concerning among others educational goals, beliefs, attitudes, willingness to innovate, job satisfaction and perception of appropriate teacher-student relationships. Based on the comparison with this norm group of teachers, the four teachers in this research appeared to be rather average teachers, although the English teacher scored very low on willingness to innovate. Certainly they did not belong among those who could be described as computer pioneers, and they did not have experience of computer assisted lessons. However, two of them used a computer at home for word processing.

Their views about the use of computers in teaching differed. The Geography and French teachers held positive views. They expected to use computers frequently for their teaching. The History teacher in contrast can be characterised as critical but positive. He had some critical comments about the way they should be used in education. The English teacher had several worries and fears about the use and implications of computers for his teaching situation.

\section{THE RESULTS}

After a year and a half of computer use the teachers had tried seven types of computer assisted lessons (CALs) as shown in Table 2 opposite. These types of lessons have been categorized according to the computer configurations and pedagogical settings involved. CAL organization types 1 to 7 relate to categories of computer assisted lesson delivery, including lesson types involving whole classroom teaching with one computer, (Type 1), different uses of two or three computers in the classroom by four or six students (Types 2 through 5), and use of the computer laboratory with whole or half classes (Types 6 and 7). 


\begin{tabular}{|c|c|c|c|c|}
\hline Types of CALs & French & English & Geography & History \\
\hline CAL 1: The electronic blackboard & 12 & 9 & 28 & 14 \\
\hline $\begin{array}{c}\text { CAL 2: Computer use as working apart } \\
\text { together }\end{array}$ & 19 & 5 & - & - \\
\hline $\begin{array}{l}\text { CAL 3: Rotating group work, with } \\
\text { computer as one setting }\end{array}$ & 5 & - & - & - \\
\hline $\begin{array}{c}\text { CAL 4: All students using media, } \\
\text { including computers }\end{array}$ & 30 & - & 4 & - \\
\hline $\begin{array}{l}\text { CAL 5: Voluntary extra work with } \\
\text { computers }\end{array}$ & 17 & - & 14 & 4 \\
\hline $\begin{array}{c}\text { CAL 6: Computer lab work without } \\
\text { support of technical assistant }\end{array}$ & 23 & 2 & 13 & 15 \\
\hline $\begin{array}{c}\text { CAL 7: Computer lab work with } \\
\text { support of technical assistant }\end{array}$ & 19 & 2 & 6 & - \\
\hline Totals & 125 & 18 & 65 & 33 \\
\hline
\end{tabular}

Table 2: Categorisation of the computer assisted lessons of the four teachers during the research period of August 1989 - January 1991

The teachers appeared to be quite different in their use of these different categories. Not only did the number of computer assisted lessons the teachers organised vary considerably, but the variety of types of computer assisted lessons also differed extensively among the teachers.

\section{The French teacher}

Of the four teachers, the French teacher used computers the most and he used them in all the different types of CALs. He said that he was conducting "experiments" in order to find out in what pedagogical settings he could best achieve the goals he had in mind. His goals were related to himself as a teacher and to his beliefs and skills with regard to the pedagogy of his subject matter. He used computers mainly for three purposes: to give information to the whole class, for remedial purposes and for drilling grammar and vocabulary. The CAL settings he used most frequently had pedagogical settings that he had mastered best in his regular teaching. Experience with these CALs gave him the opportunity to prepare himself for the use of CALs with more complex pedagogical settings, such as those involving group work (CAL Type 3). He had little experience with organizing group work; he thought it would require intensive changes to his teaching and be difficult to implement as he would have to manage different groups of students at the same time. As 
far as his pedagogy was concerned, he considered himself as an advocate of a communicative approach of foreign language teaching. Nevertheless he also believed in drilling vocabulary and grammar. He frequently said:

"You know, repeating vocabulary and grammar is always useful to do. Computers can help with that."

In his attempts to integrate computers in his classroom practice, this experienced French teacher was, on the one hand, concerned with his own learning process, trying to enhance his pedagogical skills in a step by step manner. On the other hand, his belief in the usefulness of grammar and vocabulary strongly influenced his choice of instructional uses of computers. His general view on the educational value of computers played another part in his computer activities. He thought that computers motivated students and led them to work independently, which in his view should be the way for the future.

\section{The English teacher}

In contrast to the French teacher, the English teacher used computers only sporadically. He started by using the computer several times in wholegroup classroom teaching situations "for fun" by doing word-gaming. But technical limitations of the LCD-screen stopped him from further use of the computer for whole-group classroom teaching. Occasionally he later used his classroom computer for remedial purposes. Students who had poor scores on some tests could work two by two on the computer while the rest of the students worked in a ordinary whole-group classroom setting. These computer activities, he said, were very disappointing. His classroom order was disturbed considerably by the fact that he had the computer using students rotate approximately every ten minutes. Students were excited and talked a lot.

The teacher initially thought that computers could be useful for writing. In his view it was compulsory however, to train students in the technical skills needed for word processing first. He thus started a word processing course in the computer lab, but here again his experience was negative. By the end of 1989 he stopped his teaching activities with computers in school. He attributed his negative experience to a lack of motivation on the part of the students and to the size of his classes. But most of all, he complained that the software he was familiar with did not suit the textbook he was using closely enough. Moreover, in his opinion, the software did not add any educational value to his lessons. Finally, using computers did not suit his "teacher-centred" teaching style. He 
considered computers only to be useful in very small classes with very motivated students.

This teacher clearly shows the predominant influence of beliefs and skills in the subsequent uses a teacher makes of computers. He had little flexibility in communicative and pedagogical skills and notably he had fears of loosing control of students' activities. Moreover, he was convinced that his "teacher led" lessons were more effective than computer assisted lessons. Using computers made him deviate too much from his existing teaching skills and he did not succeed in finding a way to integrate computers in his existing teaching style. As a consequence he decided to give up trying to use computers for teaching.

\section{The Geography teacher}

The Geography teacher made use of his classroom computer and transviewer frequently. During whole-group classroom teaching he used some simulations but most of all he used the computer in his classroom as an electronic blackboard. After getting acquainted with a geographical database on national planning, he very frequently supported his instructional talk by showing graphic displays of data (maps, graphs). In that way, he said, he fitted the computer seamlessly into his expository teaching style.

He also regularly went to the computer lab with his classes to work on geographically oriented computer simulations. As these lessons represented new pedagogical settings for the teacher, he prepared them thoroughly. He wanted to keep control over the students' learning process. Students received precise instructions on every step they had to make as "he did not want them to get lost in the courseware." He was surprised to find out that students were motivated and quickly found their own way in the software.

Over time his preparation time of computer assisted lessons diminished considerably and he started using the accompanying written materials provided by the publisher. When students asked the teacher for courseware to help them to prepare for their examinations, he enabled them to use the classroom computer or the computer lab during recreation time or after school time.

The Geography teacher is another example of fitting computers into existing teaching skills. He was most pleased when using computers in his teacher centred lessons. Those were the lessons he which he was very familiar, so he felt confident in this pedagogical setting. However, he consciously enhanced his teaching experience by working in the computer 


\section{Integrating information technology into education}

lab. He said that he was aware of his predominant use of whole-group classroom teaching and he wanted to reduce its frequency.

\section{The History teacher}

Although the History teacher was critical about the use of computers in teaching, he admitted he saw some advantages for using computers in his lessons. He said that computers stimulate an explorative learning approach and motivate students in history. Nevertheless he used the computer less as part of his regular routine than the French and Geography teachers. In addition to what he saw as a serious lack of software in his domain and his concern about fitting courseware in the curriculum, his relatively little use of computers can be explained by his preference for expository teaching. He held a strong pedagogical view that a history teacher should always start the learning process of students by telling them the general social-economic and political backgrounds to historical events:

"I don't believe that students will get a real understanding of history by analyzing piles of original documents or texts and reading simple facts. For the historical insight in events students need first a general background of the historical epoch in which events occur."

And this general background was, in his opinion, lacking in historical course-ware. Apparently, the educational paradigm of the History teacher did not match the paradigm of the courseware available to him, courseware that was oriented toward inquiry learning. On the one hand, the History teacher fitted the use of courseware into his pedagogical view on his subject matter. On the other hand, however, he also tried to enhance his teaching skills by working in the computer lab.

\section{The home use of computers}

All the teachers used their computers at home frequently and intensively for word processing. The four teachers considered this computer application as very useful and time-saving. This use appealed to their need for efficiency. The preparation of lessons took the Geography and French teacher about one-fifth of the time spent at home. The Geography teacher prepared his lessons carefully, especially in the beginning. On the contrary, the History teacher preferred not to spend too long in preparing his lessons and liked to try out things and see the results in practice.

Although the teachers showed significant differences in computer uses in the classroom, they all spent about two-and-a-half hours a week at their computers at home. The four teachers felt this to be an acceptable time in their normal weekly work load. 


\section{Two years after}

As far as the use of computers for teaching is concerned the teachers significantly reduced their activities between 1991 and 1993. One of the reasons for this decline in activities was that during these years the researchers withdrew from school and data were collected only by interviews once a year. The use of computers in teaching situations that occurred were predominantly related to the use of drill and practice software such as the training of grammar, vocabulary and preparation for final exams. According to their preferred teaching styles, the teachers used computers in teaching settings with which they were already familiar. Thus, the History teacher let his students use software to help them prepare their exams, and the French teacher continued using computers in his classroom with four to six computer-using students. The Geography teacher met serious problems in getting new hardware for his expository teaching which resulted in no use of the computer in his classroom.

Although the English teacher bought a new textbook in which the use of software was an integrated teaching activity, he found a way to avoid computer assisted teaching situations in which he feared to loose control over his students. He gave the software to his students who were to work with it at home.

After four years of computer experience, the teachers' views on computer assisted teaching appeared hardly to have changed. Their beliefs on what should be in the curriculum of their subject matter and the way this content should be taught determined to a large extent their uses of computers. Although the teachers said they wanted to reduce their central role in their lessons, none of them had succeeded in putting this into practice by using the computer.

\section{FACTORS INFLUENCING THE TEACHERS' USES OF COMPUTERS}

After analyses of the case studies, two major categories of factors explaining the uptake of computers by the four teachers have been discerned: factors at the school level and factors at the teacher level.

\section{School-level factors}

School factors played an important role in how the teachers made use of their computers. First, the support of the technical assistant was essential for the teachers. Not only did they count on his support for tasks such as making copies of software, they more significantly relied on his collaboration during many of their computer assisted lessons in the 


\section{Integrating information technology into education}

computer lab. Secondly, the principal played an important role. She held a positive view on information technology in education and she provided the necessary technical support for the teachers by allocating a technical assistant for twenty hours a week. Moreover, she established an IT committee to be a platform for discussion and computer related policy making. Financial support was given to the teachers so that they could purchase the required software. And last but not least, the principal gave moral support through informal talks with the teachers showing her commitment and interest in their efforts.

\section{Teacher-level factors}

However, teacher factors outweighed the school factors in explaining how the teachers' used computers. These teacher level factors could be grouped into two sub-categories: beliefs and skills. Most important of these were teachers' beliefs regarding what should be in the curricula (content) and the way in which the subject should be taught (pedagogy).

Teachers also had beliefs regarding their role in the classroom and the corresponding classroom activities. Finally they had personal views on education and on themselves as teachers that also influenced what they did with the computers.

The skills of teachers that most influenced their uses of computers were those skills related to their competence in managing classroom activities, to their pedagogical skills and, less importantly, to their computer handling technical skills. These inter-related beliefs and skills can briefly be described of as "routines".

In summary, the uptake of computers in the classroom was strongly affected by the beliefs and skills or 'routines' of the four teachers. They tried to fit information technology into pedagogical approaches consistent with their beliefs and their skills. Although three of the teachers tried to enhance their skills, their beliefs were hardly changed by the influence of information technology.

\section{RESULTS OF OTHER RESEARCH}

Comparing the results of our study with that of other research, we have found a considerable consistency in findings. Some common findings can be identified.

\section{Persistence of beliefs}

Ten years after Fullan [2] stated that "educational change depends on what teachers think and do" (p. 107), he stressed the importance of this 
statement by identifying the beliefs of teachers as very critical elements in educational innovations. Teachers hold views that persist during innovations. Educational change is a slow process and teachers need time to gain experience with computers. In a nation-wide survey simultaneously with a number of case studies, Watson [3] concluded that teachers' beliefs and their resulting teaching styles changed very little over time:

"... teachers using IT often considered that computers were to be used to complement rather than change existing pedagogic practice, whether it be 'traditional' or 'progressive' (p. 160)".

In the majority of their use of computers, the teachers in our case studies did little that could be described as exploiting the overwhelming educational possibilities of information technology so often described in literature [4, 5 and 6]. They did not even consider these possibilities. Instead, they started using the computers for their own convenience by doing word processing. Then they carefully set out for the use of computers in classrooms where they varied pedagogical conditions as less as possible. Gradually, they experimented with pedagogical settings that were more difficult for them.

The persistence of beliefs of teachers during innovations is also supported by Olson \& Eaton [7], Martin [8], Carmichael et al. [9] and Rubin \& Bruce [10]. These authors all stress the influence of existing classroom routines. Teachers have standardized behaviours and it is "through such routines that teachers express their ideas of how classroom life is to be conducted" (Olson [11]).

\section{Fitting into beliefs and skills}

As a consequence of the predominant influence of teachers' beliefs on educational change, many authors support our view that innovative activities should fit existing beliefs and skills of teachers. As Olson [11] states:

"...We can now see that classroom routines are not what computers will replace, they are where computers must fit if they are to be useful to teachers..."

Wiske et al. [12, 13 and 14] found that beliefs related to subject specific pedagogy are critical in innovative activities of teachers. In their view, teachers' need to adapt innovations stems from their preferred teaching styles and values. This need for adaptation is also reported by Rubin \& Bruce [10] who conclude that in their study teachers "create new practices 
that reflect complex and situation-specific combinations of old and new approaches" (p. 2).

This orientation might upset some advocates of information technology. However, only by acquiring positive experiences with computers in a way that teachers do appreciate, is there a chance that their newly developed skills will start to change their beliefs. For any educational innovator it is important to realise that it is not the view of the innovator about the merits of the innovation that matters, but rather it is the view of the teachers about the innovation that is critical. If teachers start using computers for drill and practice only, it is probably that use that fits their routines best. Their learning process should not be disturbed by telling them that doing drill and practice with computers is only a poor application of information technology. Perhaps it will be only after two or three years that teachers can gradually enhance their routines and handle more complex applications of information technology.

\section{Importance of the support of the principal}

A third conclusion that emerged from our case studies is also well supported in the literature: the implementation of innovations should not be the task of individual teachers only [15, 16, 17 and 18]. The school management also has to be involved financially as well as through policy and moral support. As change is a slow process, it is essential that school managers look far ahead and persist in their support of change. In our research, two years of innovative activities appeared only to be the beginning for an integrated uptake of computers for two of the teachers. School managers should realise that not all teachers in the school are equally interested in educational change, particularly change involving information technology. A differentiated bottom-up approach for the different subject-area departments in the school seems to fit the school reality the best.

\section{Importance of school culture}

By the end of the eighties, a critical issue in literature about educational change has been the influence of the school culture on innovations $[7,13$, $15,17,19,20]$. Sheingold et. al. [15] observed that in schools with a "do your own thing ethic", innovative activities were likely to stay restricted to some individual pioneers in the school. Schools with a culture of collaboration between teachers gave way to the pioneers to share their ideas with other teachers. The results of our case studies do support this findings in that the teachers worked within a non-collaborative school 
culture in which colleagues did not give any feedback on their enthusiastic efforts to implement computers in their instructional practice.

\section{A DESCRIPTIVE MODEL}

Factors affecting the uptake of computers in the classroom appear to be strongly interrelated. In order to visualize the relations between the different factors, we have developed a descriptive model (see below).

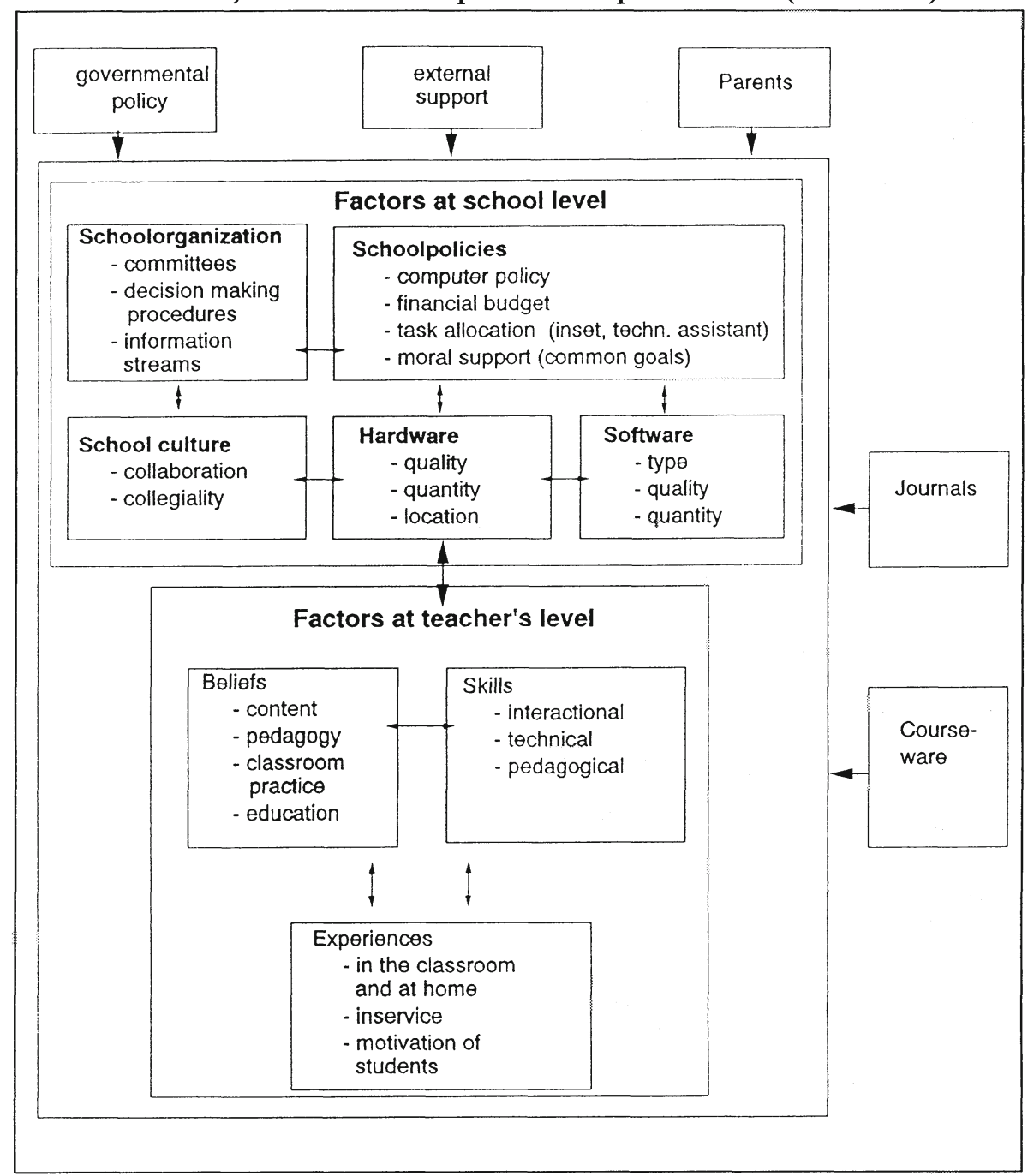

Figure 1: A descriptive model of factors affecting computer use in schools. 
The model is based on our case studies as well as the synthesis of 32 other case studies [21, 22 and 23]. It gives a comprehensive overview of all the factors that were considered by the researchers as relevant and about which exists a certain consensus. Although the model gives a clear picture of the interrelationship of factors it is limited by the fact that no weight of factors can be discerned. Nevertheless, we should like to propose as a hypothesis that the model could offer a framework for analyzing the chances of success of the implementation of computers in schools.

\section{REFERENCES}

1. Yin, R. K. (1989) Case Study Research, Design and Methods. Newbury Park, CA: Sage Publications.

2. Fullan, M.G. (1982) The meaning of educational change. Toronto: OISE Press, and New York: Teachers College Press.

3. Watson, D.M., ed. (1993). The Impact Report: An evaluation of the impact of information technology on children's achievements in primary and secondary schools. London: Department for Education and King's College London, Centre for Educational Studies.

4. Summers, E.G. (1985) Microcomputers as a New Technological Innovation in Education: Growth of the Related Journal Literature. Educational Technology, August 1985, 5-14.

5. Whiting, J., (1985) New Directions in Educational Computing: Coming Changes in Software and Teaching Strategies to Optimize Learning. Educational Technology, September 1985, pp. 18-21.

6. Norton, P. (1985) An Agenda for Technology and Education: Eight Imperatives. Educational Technology, January 1985, pp. 15-20.

7. Olson, J., Eaton, S. (1986) Case Studies of Microcomputers in the Classroom, Questions for Curriculum and Teacher Education. Toronto: OISE Publication Services.

8. Martin, C.D. (1991) Stakeholders/perspectives on the implementation of micros in a schooldistrict. In: R.L. Blomeyer Jr. \& C.D Martin (Eds.), Case studies in computer aided learning, pp. 169-221. London: The Falmer Press. 
9. Carmichael, H.W., Burnett, J.D., Higginson, W.C., Moore, B.G. \& Pollard, P.J. (1985) Computers, children and classrooms: A multisite evaluation of the creative use of micro-computers by elementary school children. Ontario, TO: Ministry of Education.

10. Rubin, A., \& Bruce, B. (1990) Alternate realizaitions of purpose in computer-supported writing (technical report No. 492). Champaign: University of Illinois, Center for the study of reading (ERIC Document Reproduction Service No. ED 314 760).

11. Olson, J. (1992) Trojan horse or teacher's pet? Computers and the teacher's influence. International Journal of Educational Research, 17 (1), 77-85.

12. Wiske, M.S. et al. (1988) How technology affects teaching. Cambridge, MA: Harvard Graduate School of Education and Education Development Center. Educational Technology Center.

13. Shepard, J.W., Wiske, M.S. (1989) Extending technological innovations in schools: Three case studies and analysis. Cambridge, MA: Harvard School of Education, Educational Technology Center (ERIC Document Reproduction Service No. ED 303 372).

14. Wiske, M.S., Houde, R. (1988) From recitation to construction: Teachers change with new technologies. Cambridge, MA: Harvard Graduate School of Education, Educational Technology Center.

15. Sheingold, K., Kane, J.H., \& Endreweit, M.E. (1983) Microcomputer use in schools: Developing a research agenda. Harvard Educational Review, 53 (4), 412-432.

16. Cox, M., Rhodes, V., \& Hall, J. (1988) The use of computer assisted learning in primary schools: Some factors affecting the uptake. Computers and Education, 12 (1), 173-178.

17. Fullan, M.G. (1992a) Successful School Improvement. Buckingham: Open University Press.

18. Fullan, M.G. (1992b) Teacher Development and Educational Change. London: The Falmer Press.

19. Sarason, S.B. (1982) The culture of the school and the problem of change (2nd ed.). Boston: Allyn and Bacon.

20. Sikes, P.J. (1992) Imposed change and the experienced teacher. In: M. Fullan \& A. Hargereaves (Eds.), Teacher Development and educational change, pp. 36-55. London: The Falmer Press. 
21. Veen, W. (1993) How teachers use computers in instructional practice: Four case studies in a Dutch secondary school. In: Moonen, J.J. \& Collis, B (eds.), Computers and Education, 21 (1/2), 1-8.

22. Veen, W., Vogelzang, F., Neut v.d. A. C., Spoon, P.P. (1992) How computers are used in the instructional practice. In: Plomp, T., Pieters, J. $\&$ Feteris, A. (eds.), Proceedings of the European Conference on Educational Research (ECER) 2, 446-454. Enschede: Twente University Press.

23. Veen, W. (1994) Computerondersteunde docenten; de rol van de docent bij de invoering van computers in de klaspraktijk. (Computer assisted Teachers; The Teacher's role in the implementation of computers in the instructional practice). Diss. De Lier: Academisch Boeken Centrum.

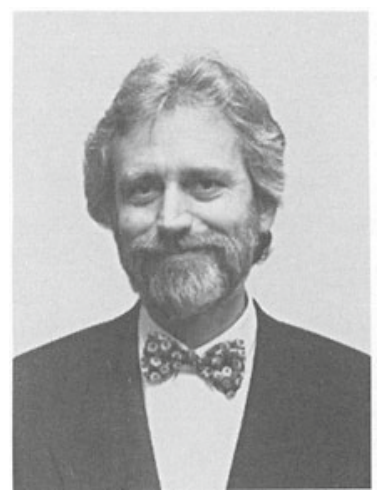

Wim Veen has been working at the Institute of Education at the University of Utrecht since 1978. For ten years he has been a trainer of geography teachers in both initial and in-service training. In 1986 he created a research group on information technology. He has been involved in a number of IT projects related to the implementation of computers in schools, the development and translation of coursewear and the use of telecommunications. Wim is currently involved in the research on policy and planning issues with respect to the support of telecommunications in education. 